\title{
Subsidence characterization and modeling for engineered facilities in Arizona, USA
}

\author{
M. L. Rucker, K. C. Fergason, and B. B. Panda \\ Amec Foster Wheeler, Phoenix, Arizona, USA \\ Correspondence to: M. L. Rucker (michael.rucker@amecfw.com) \\ Published: 12 November 2015
}

\begin{abstract}
Several engineered facilities located on deep alluvial basins in southern Arizona, including flood retention structures (FRS) and a coal ash disposal facility, have been impacted by up to as much as $1.8 \mathrm{~m}$ of differential land subsidence and associated earth fissuring. Compressible basin alluvium depths are as deep as about $300 \mathrm{~m}$, and historic groundwater level declines due to pumping range from 60 to more than $100 \mathrm{~m}$ at these facilities. Addressing earth fissure-inducing ground strain has required alluvium modulus characterization to support finite element modeling. The authors have developed Percolation Theory-based methodologies to use effective stress and generalized geo-material types to estimate alluvium modulus as a function of alluvium lithology, depth and groundwater level. Alluvial material modulus behavior may be characterized as high modulus gravel-dominated, low modulus sand-dominated, or very low modulus fines-dominated (silts and clays) alluvium. Applied at specific aquifer stress points, such as significant pumping wells, this parameter characterization and quantification facilitates subsidence magnitude modeling at its' sources. Modeled subsidence is then propagated over time across the basin from the source(s) using a time delay exponential decay function similar to the soil mechanics consolidation coefficient, only applied laterally. This approach has expanded subsidence modeling capabilities on scales of engineered facilities of less than 2 to more than $15 \mathrm{~km}$.
\end{abstract}

\section{Introduction}

Subsidence has been analyzed at engineered facilities in Arizona for over two decades (Keaton et al., 1998; Rucker et al., 2008). Prior to developing the current Percolation Theory (PT)-based techniques, finite element model parameter studies were used to best-fit modeled subsidence profiles to available InSAR-, historic survey-, and survey-derived elevation records versus design elevation subsidence records. Alluvium material classification included well logs (ranging from commonly poor-quality historical qualitative descriptions to high-quality quantitative borehole geophysical logging) and surface geophysical measurements (especially resistivity) to supplement published data (AMEC, 2009).

\section{Modeling alluvium as percolating systems}

Basin alluvium can be modeled as networks of interconnected but highly dissimilar (heterogeneous) materials, such as interfingered lenses of finer alluvium (behavior dominated by silts and clays) and coarser alluvium (behavior dominated by sands and gravels). Connectivity of alluvium aquifer systems consisting of fines-dominated, sand-dominated or gravel-dominated units can be quantified through concepts of PT. For characterizing subsidence, three alluvium parameters are addressed using PT.

- Modulus is a function of alluvium density (porosity) as controlled by effective stress or original depositional energy. Fines-dominated, sand-dominated and graveldominated alluvium units tend to have very low, low and high modulus, respectively.

- Resistivity relates to the connectivity of the fines (silts and clays) portion of the alluvium and indicates alluvium modulus behavior and permeability characteristics. In fresh water aquifer conditions, fines-dominated, sand-dominated, and gravel dominated alluvium units typically have resistivities of less than $10 \mathrm{ohm}$-meters, 10 to about $30 \mathrm{ohm}$-meters and greater than $30 \mathrm{ohm}-$ meters, respectively. 
Example 2-D percolating matrix 'aquifer system' consists of

$62 \%$ 'sand' or aquifer (white squares)

$38 \%$ 'clay' or aquitard (black squares)

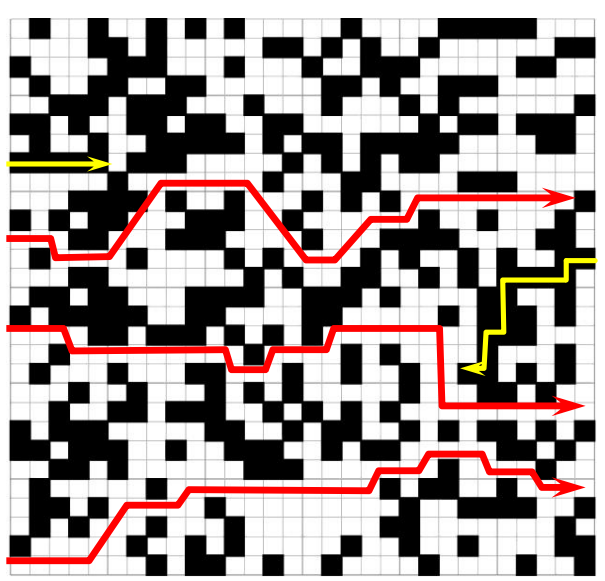

System behavior opens or closes

(begins or stops) at a matrix density

percolation threshold $P C$

For site percolation through adjoining cell sides in a matrix (as shown)

In 2-D, $P c$ is $~ 59 \%$

In $3-D, P c$ is $~ 31 \%$

High permeability proceeds through percolating 'sand' $(62 \%>59 \% P c)$ pathways (red arrows)

Low resistivity is stopped by a lack of percolating 'clay' $(38 \%<59 \%$ Pc) pathways (yellow arrows)

Behavior is fractal near $\boldsymbol{P c}$, and structure may be selfsimilar over a wide range of measuring scales:

Borehole $\mathrm{E}_{\text {short normal }} 1$ 's $\mathrm{ft}$

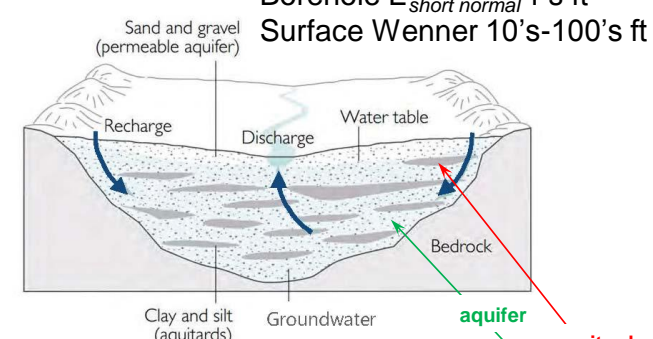
pg 6 (after Galloway 1999), LSCE and others (2014) aquitard

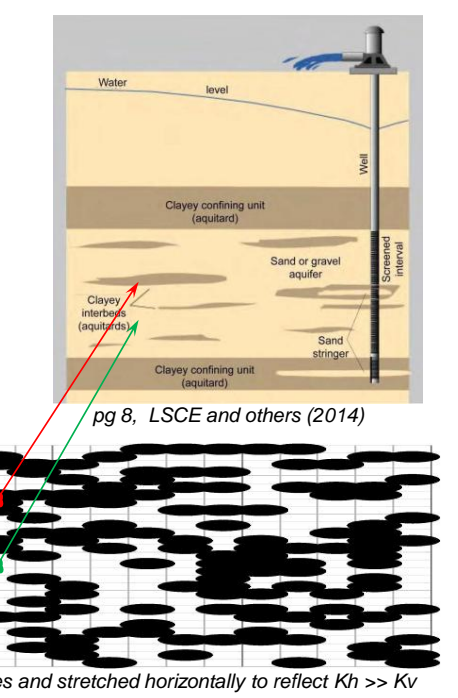

Figure 1. Basic PT (Sukop et al., 2002) site-percolation model (Fig. 1a top) is modified to address basin alluvium connectivity and behaviour (Fig. 1b bottom).

- Permeability relates to the connectivity of the coarse (sands and gravels) portion of the alluvium to indicate time delay and potential presence of a "water of compaction" confined aquifer condition. Fines-dominated, sand-dominated and gravel-dominated alluvium units typically have very low permeability (with potential water of compaction conditions), moderate permeability and high permeability, respectively.

Concepts of permeability and resistivity connectivity in an alluvial PT system (exhibiting significant randomness) are visualized in Fig. 1. Connectedness in the random matrix occurs as like squares that share a side "connect" into a continuous pathway. When a continuous pathway of connected squares across the matrix is present, then the matrix is a "percolating network". The percolation threshold (Pc) is the density of the matrix (probability in a random system) at which percolation begins. Percolating network permeable flow (from left to right), and lack of a percolating network low resistivity pathway are demonstrated in the 2-D matrix example (Fig. 1a). The same fraction of clay ( $38 \%$ in the 2-D example) in a 3-D network (Pc of $31 \%$ ) would exhibit network connectivity, and the 3-D matrix would have a moderately low resistivity.

These concepts are applied to characterize heterogeneous basin alluvium (in 3-D) as shown in the 2-D representation 

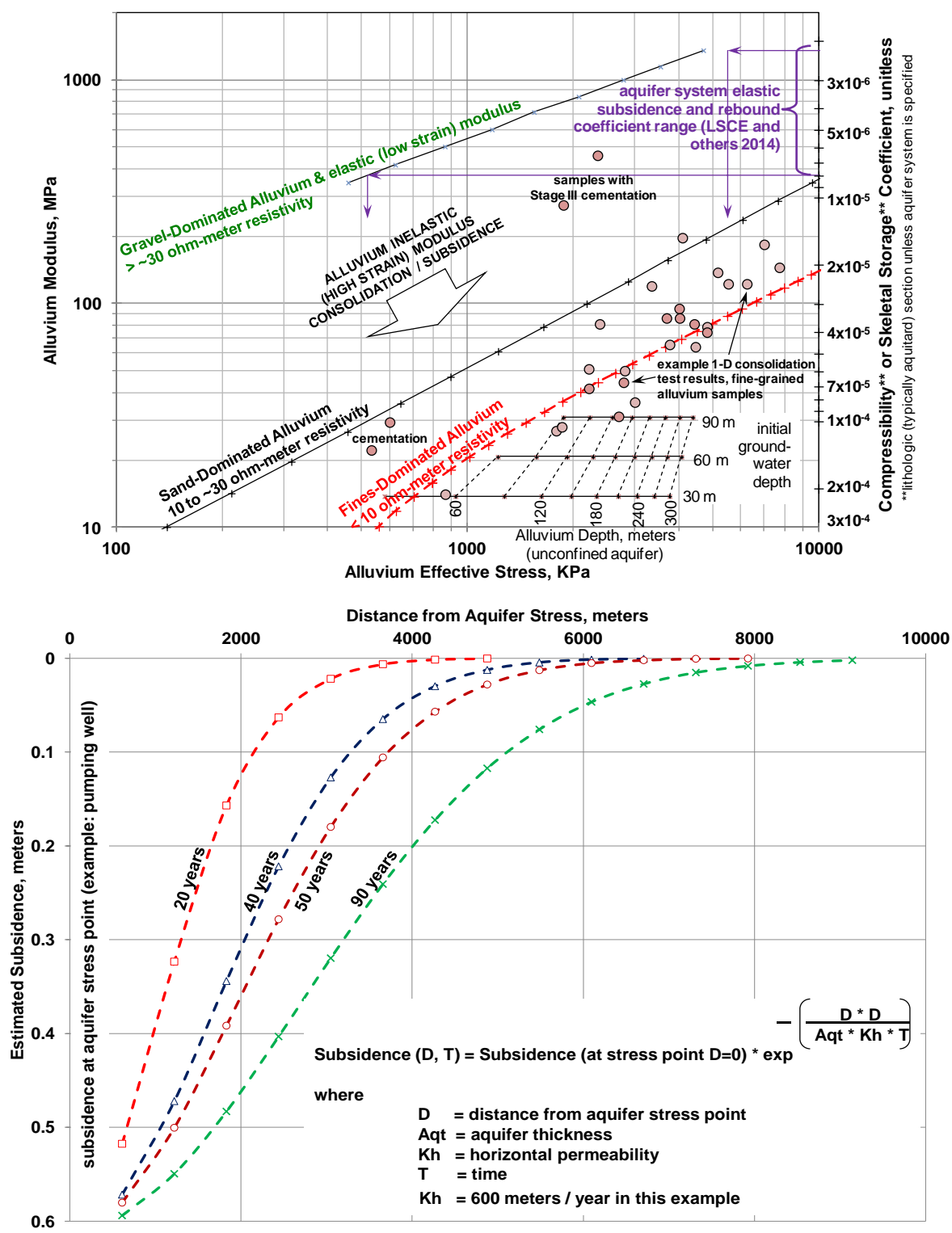

Figure 2. Subsidence modulus parameters are related to compressibility over a range of effective stress in Fig. 2a (top). Example test results are from deep wells in the east Salt River Valley, Arizona. Lateral subsidence propagation over time is shown in Fig. 2b (bottom).

in Fig. 1b. Fines-dominated alluvium and sands-dominated alluvium are most likely to contribute to significant subsidence. Sand-dominated alluvium contains significant quantities (greater than about $31 \%$ to less than about $69 \%$ ) of fines in a connected permeable sand network to provide drainage paths for those fines; sand-dominated alluvium exhibits high subsidence due to the network of moderate to high permeability material surface areas draining adjacent fine-grained materials. Gravel-dominated alluvium is likely to contribute only minor subsidence. Boundaries between these alluvium lithologies may strongly correlate with 3-D Pc thresholds defining the edges of fines-dominated to sand-dominated and sand-dominated to gravel-dominated modulus behaviors.

\section{Subsidence estimation using PT-based modulus concepts}

The objective of this PT-based subsidence modeling process is estimation of the modulus profile through the compressible alluvium. For materials consisting of a matrix of particles and porosity, PT provides means to define modulus as a threshold and power-law relationship to porosity (Sahimi, 1994), where modulus increases exponentially as porosity decreases. A PT approach to estimate elastic (low strain) modulus as a function of porosity (or density) in geomaterials is presented in Rucker (2008). A relationship of inelastic (high strain) modulus relative to elastic modulus is 
modeled as a power-law (Rucker, 2008) anchored at very low modulus by sand (Seed and Idriss, 1970) and at very high modulus by rock (van Heerden, 1987). Finally, an approach to relate inelastic modulus to effective stress is presented in AMEC (2009). Starting with a material at low density (high porosity), a modeled incremental reduction of porosity becomes a modeled strain. From that strain, and an average of the modulus at initial and incremented porosity, a stress may be calculated. This process is incremented over a range of decreasing porosity, so that density and modulus increase as a function of the accumulated applied stress. Resulting estimated initial consolidation high strain modulus trends for alluvium as a function of effective stress, and thus depth and groundwater levels, are presented in Fig. 2a. Lateral propagation of subsidence over time, where horizontal permeability is the primary alluvium material parameter, is demonstrated in Fig. 2b.

\section{Comparison of USGS and PT approaches to subsidence characterization}

The PT approach appears to be consistent with USGS concepts (Helm, 1975) since compaction parameters (compressibility or skeletal storage coefficients, typically determined using compaction extensometers) are an inverse relation to PT-based modulus as shown in Fig. 2a. An example of this consistency is the range of alluvium elastic modulus and alluvium effective stress compared with the range of aquifer system elastic subsidence and rebound coefficient (purple arrows in Fig. 2a) as reported by LSCE, Borchers and Carpenter (2014). Individual laboratory-scale, relatively undisturbed soil samples (fine-grained sediments) obtained for subsidence studies (circle symbols in Fig. 2a), tend to behave as and relate best to the fines-dominated modulus trend. The fines-dominated modulus trend is about half the modulus of the sand-dominated modulus trend; an alluvium matrix including a mix of inelastic fines material and elastic coarse material (Fig. 1b) reflects an overall sand-dominated modulus utilizing the PT approach.

\section{Results and conclusions}

Reasonable estimates of basin alluvium modulus facilitate calculation of subsidence. Modeled results have had typical estimate errors of about $10 \%$ with standard deviations of about 30 to $40 \%$ compared to available project historic survey point data. Once historical subsidence has been modeled, rational future predictions and projections have been made to inform long-term design criteria for facility rehabilitation.
Acknowledgements. The strong support and encouragement of the Flood Control District of Maricopa County, Arizona and the Arizona Electric Power Cooperative, Inc., was essential in the development and application of the new concepts and methods described in this paper.

\section{References}

AMEC E and E, Inc.: White Paper, in Procedural Documents for Land Subsidence and Earth Fissure Appraisals, for Flood Control District of Maricopa County, Phoenix, AZ, available at: ftp://ftp.mcdot.maricopa.gov/anonymous/FCD (last access: 22 October 2015), 2009.

Galloway, D. L., Jones, D. R., and Ingebritsen, S. E.: Land subsidence in the United States, US Geological Survey Circular, Reston, Virginia, 1182, 177 pp., 1999.

Helm, D. C.: One-dimensional simulation of aquifer system compaction near Pixley, California - 1. Constant parameters, Water Resour. Res., 11, 465-478, 1975.

Keaton, J. R., Rucker, M. L., and Cheng, S.: Geomechanical Analysis of an Earth Fissure Induced by Ground-Water Withdrawal for Design of a Proposed Ash and Sludge Impoundment, Southeastern Arizona, Land Subsidence Case Studies and Current Research: Proceedings of the Joseph F. Poland Symposium on Land Subsidence, 4-5 October 1995, Spec. Publ. No. 8, AEG, Star Publishing Co., Belmont/CA, 217-226, 1998.

LSCE: Luhdorff \& Scalmanini Consulting Engineers, Borchers, J. W. and Carpenter, M.: Luhdorff and Scalmanini Consulting Engineers (LSCE), Land Subsidence from Groundwater Use in California, Full Report of Findings, California Water Foundation, 9-10, April 2014.

Rucker, M. L.: Estimating in-situ geo-material mass density, modulus and unconfined compressive strength from field seismic velocity measurements. Highway Geophysics - Nondestructive Evaluation Conference, Charlotte, NC, 1-4 December, available at: ftp://ftp.mcdot.maricopa.gov/anonymous/FCD (last access: 22 October 2015), 2008.

Rucker, M. L., Greenslade, M. D., Weeks, R. E., Fergason, K. C., and Panda, B. B.: Geophysical and Remote Sensing Characterization to Mitigate McMicken Dam, in: GeoCongress 2008: Geosustainability and Geohazard Mitigation (GSP 178), edited by: Reddy, K. R., Khire, M. V., and Alshawabkeh, A. N., 207-214, American Society of Civil Engineers, doi:10.1061/40971(310)26, 2008.

Sahimi, M.: Applications of Percolation Theory, Taylor \& Francis, Bristol, Pennsylvania, 181-186, 1994.

Seed, H. B. and Idriss, I. M.: Soil Moduli and Damping Factors for Dynamic Response Analysis, Report No. EERC 70-10, Earthquake Engineering Research Center, University of California, Berkeley, California, p. 19, 1970.

Sukop, M. C., Van Duk, G., Perfect, E., and Van Loon, W. K. P.: Percolation thresholds in 2-dimensional prefractal models of porous media, Transport in Porous Media, Vol. 48, 187-202, Kluver Academic Press, the Netherlands, 2002.

van Heerden, W. L.: General Relations Between Static and Dynamic Moduli of Rocks, Int. J. Rock Mech. \& Geomech. Abstr., 24, 381-385, 1987. 